\title{
Short-Term \\ Dynamic Psychotherapy
}

Evaluation and Technique

$$
\text { SECOND EDITION }
$$




\section{TOPICS IN GENERAL PSYCHIATRY}

Series Editor:

John C. Nemiah, M.D.

Professor of Psychiatry, Dartmouth Medical School and Professor of Psychiatry Emeritus, Harvard Medical School

\section{THE FRONTIER OF BRIEF PSYCHOTHERAPY}

David H. Malan, D.M., F.R.C. Psych.

\section{HYPNOSIS}

Fred H. Frankel, M.B.Ch.B., D.P.M.

\section{THE PRACTITIONER'S GUIDE TO PSYCHOACTIVE DRUGS}

\section{Second Edition}

Ellen L. Bassuk, M.D., Stephen C. Schoonover, M.D., and Alan J. Gelenberg, M.D.

\section{SHORT-TERM DYNAMIC PSYCHOTHERAPY}

Evaluation and Technique

Second Edition

Peter E. Sifneos, M.D.

SOCIOCULTURAL ROOTS OF MENTAL ILLNESS

John J. Schwab, M.D., and Mary E. Schwab, M.D. 


\title{
Short-Term \\ Dynamic Psychotherapy \\ Evaluation and Technique
}

\author{
SECOND EDITION \\ Peter E. Sifneos, M.D. \\ Harvard Medical School \\ Boston, Massachusetts
}

Springer Science+Business Media, LLC 


\title{
Library of Congress Cataloging in Publication Data
}

Sifneos, Peter E. (Peter Emmanuel), 1920-

Short-term dynamic psychotherapy.

(Topics in general psychiatry)

Bibliography: $p$.

Includes index.

1. Psychotherapy, Brief. 2. Anxiety. I. Title. II. Series. [DNLM: 1. Anxiety. 2. Interview, Psychological. 3. Psychotherapy, Brief. WM 420 S573sb]

First Printing-May 1987

Second Printing - February 1990

\author{
ISBN 978-1-4899-0845-2 ISBN 978-1-4899-0843-8 (eBook) \\ DOI 10.1007/ 978-1-4899-0843-8
}

(C) Springer Science+Business Media New York 1987

Originally published by Plenum Press, New York in 1987

Softcover reprint of the hardcover 2nd edition 1987

\section{All rights reserved}

No part of this book may be reproduced, stored in a retrieval system, or transmitted in any form or by any means, electronic, mechanical, photocopying, microfilming, recording, or otherwise, without written permission from the Publisher 
TO JEANNETTE

Understanding and warm

Tolerant and magnanimous

A tower of strength

A beloved sister 


\section{Foreword to the Second Edition}

In the seven years since Dr. Sifneos's Short-Term Dynamic Psychotherapy first appeared, it has become one of the classic works on the subject. Its publication played a large part in establishing that form of treatment on a solid foundation. Today, short-term psychotherapy is no longer viewed as a shabby stepsister to psychoanalysis and long-term psychoanalytic psychotherapy; Cinderella has at last come of age, decked out in the finery of widespread clinical usage and celebrated in a literature that now numbers hundreds of papers and monographs.

The basic principles and techniques of short-term anxiety-provoking psychotherapy (STAPP) - the particular form of brief therapy developed by Dr. Sifneos-remain much as they were presented in the earlier edition of this book. There have, however, been important developments over the past decade both in the field and in Dr. Sifneos's own conceptions. These have mandated a revised and expanded edition of the original volume in order to provide the reader with a review of the recent literature, a reassessment of the effectiveness of STAPP, a discussion of its expanded application to patients with somatic symptoms and abnormal grief reactions, and its usefulness in treating older persons.

A particular virtue of the earlier edition was its presentation of 
extensive verbatim material from the author's therapeutic sessions with his patients. That feature not only has been maintained in this volume but has been greatly expanded to include new clinical cases derived from Dr. Sifneos's continued practice and observation. Like its predecessor, this edition provides an excellent guide for the beginning psychiatrist and a reinvigorating inspiration for the seasoned therapist.

JOHN C. NEMIAH, M.D. 


\section{Foreword to the First Edition}

Short-term psychotherapy, although brief, is not ephemeral. In the decade or two of its existence, it has grown into a sturdy tree, and a sign of its maturity is the fact that it is now the subject of an increasing number of overview articles summarizing its literature and findings. Yet it remains a young and vigorous discipline. Its pioneers have not been elevated to a pantheon of venerable but mute immortals; on the contrary, they are to be found at the forefront of the field, actively contributing to the development of its theory and practice. This volume is ample testimony to their continued creativity.

Dr. Sifneos has lectured and written extensively about short-term anxiety-provoking psychotherapy (STAPP). Based on psychoanalytic principles, STAPP aims to resolve pathological psychic conflicts and help those suffering from them to learn new ways of being in their most intimate relationships. It does so by actively focusing the patients' sights on their Oedipal problems, and its effectiveness (given a proper selection of subjects by specific criteria) has been amply documented in controlled clinical studies.

One of the significant virtues of Dr. Sifneos's therapeutic techniques is that they can be systematically taught to the aspiring psychotherapist. Dr. Sifneos has touched briefly on his procedures here and there throughout his published writings, but detailed 
information about his approach has been restricted to those fortunate enough to have direct vivia voce instruction through his didactic lectures and clinical supervision. Now, in this volume, he devotes his attention singly and entirely to the practical details of his method of short-term psychotherapy and does so with a clarity that arises from the demonstration of actual encounters with patients in therapeutic interviews. Step by step, Dr. Sifneos takes the reader through the evolution of the treatment process as this occurs with real individuals undergoing therapy.

The careful study of his exposition will not in itself make one an expert psychotherapist; that, of course, can come only from applying one's knowledge in the active, repeated practice of the art. But the reader can be assured of discovering exactly what he needs to know and do to become proficient in the therapeutic method Dr. Sifneos describes. That is the first and major step to effective and lasting learning.

JOHN C. NEMIAH, M.D. 


\section{Preface to the Second Edition}

During the past eight years the demand for short-term dynamic psychotherapy has continued to increase and, at the present time, this kind of treatment is offered to more and more patients, clearly establishing that it is a major addition to the therapist's armamentarium.

Criticism from those advocating the advantages of long-term psychotherapy, as well as the hostility of the news media, has diminished. Specificity has prevailed, and different types of psychotherapy of long-term or brief duration have been shown to be effective for well-selected groups of patients.

In the United States, despite the interest in short-term therapies shown by governmental agencies and third-party payers such as the insurance industries, no funds have been provided to support research on their outcome or the education of great numbers of mental health professionals who seek training in this field. As a result of this unfortunate state of affairs there exist very few centers in this country which offer the opportunity to develop the skills and learn the techniques of short-term dynamic psychotherapy.

It is significant, nevertheless, that the enthusiasm of a few workers in the field of short-term dynamic psychotherapy has remained high, and research studies using videotapes to demonstrate 
the evaluations, techniques, and outcome have helped to document the efficacy of their therapeutic modalities. In addition, many good books and articles have been published introducing new concepts, such as the importance of systematic case studies and personality styles by Horowitz, a variety of brief therapies by Budman, and an integrating model of time-limited psychotherapy by Strupp, to mention only a few.

The investigation of the efficacy of short-term anxiety-provoking psychotherapy (STAPP), which is the subject of this book, has continued during the last eight years, particularly in reference to patients with unresolved Oedipal conflicts. The chapter on outcome has therefore been expanded to include some of our findings.

Cautious attempts have also been made to utilize focal and innovating techniques for the treatment of individuals with borderline as well as compulsive personalities.

In this second edition an effort has been made to present the specific technical factors which seem to have a therapeutic effect, such as problem solving, self-understanding, and new learning, and which are utilized by the patients to solve new emotional conflicts long after the end of their treatment.

Chapters on the treatment of elderly patients and the handling of individuals with physical symptomatology have been added; a history of the extensive treatment of a male patient has been presented to complement the discussion of the therapy of my female patient which appears in Appendix I.

Finally, I want to express my gratitude to all those in practically every state in this country, as well as in Canada, Switzerland, Belgium, Holland, all of the Scandinavian countries, Italy, and Greece, who invited me to speak and who organized workshops where I could present my work and my videotapes. This invaluable support has been heartwarming and has become a motivating force for me to pursue this fascinating work. I am forever indebted to them.

Peter E. Sifneos 


\section{Preface to the First Edition}

During the last few years, dynamic psychotherapies of brief duration have suddenly become very popular. Although a few investigators studied these kinds of treatment methods systematically over a long period of time and were convinced of their effectiveness, the recent emphasis on primary care, the increased national health insurance coverage, and the documentation which has been provided pointing to tangible therapeutic results, even in patients with serious neurotic difficulties, have aroused a great deal of interest in these treatment modalities all over the world. The familiar criticisms from advocates of long-term psychotherapy are more subdued, and one hears less often the pompous pronouncement that psychotherapy is unscientific. For all intents and purposes, therefore, it seems that short-term psychotherapy is here to stay.

Time limitation is, of course, a crucial factor in all brief therapies, yet it is paradoxical that there is no consensus among the workers in this field as to exactly what is meant by this concept. It should be emphasized from the start, however, that the primary reason for shortening the time interval is not because of demands that more services be made available to patients in the community at large. Rather, the governing force behind any kind of therapeutic 
intervention should be the documentation that it is a treatment well suited to each patient's idiosyncratic needs. In this respect, certain kinds of brief therapy are indeed indicated for a fairly large group of well-selected patients.

Some of these issues have been dealt with in my book ShortTerm Psychotherapy and Emotional Crisis (Sifneos, 1972) in a more general way. Because of a certain prevailing confusion, however, and to avoid misunderstandings, I shall elaborate my ideas about short-term dynamic psychotherapy more extensively in the present volume. Furthermore, instead of writing only one chapter about the evaluation of the patient and one on the technique, as I did in my previous book, I shall concentrate on presenting as systematically as possible the psychiatric evaluation of a well-selected group of patients. In addition, I shall give a detailed description of the technique of a specialized kind of psychotherapy of short duration, called "anxiety provoking." In order to illustrate convincingly what I am discussing, I have used as many verbatim clinical vignettes as possible so as not only to demonstrate as explicitly as I can how shortterm dynamic psychotherapy should be performed but also to encourage many therapists to utilize it in their everyday practice.

"Anxiety-provoking" psychotherapy utilizes the patient's anxiety as a motivating force to help him resolve his difficulties. Because it is also of short-term duration, it will be referred from now on as STAPP (Short Term Anxiety-Provoking Psychotherapy).

STAPP is not the only kind of brief dynamic psychotherapy. Malan $(1976 a, b, c)$ has described a technique of brief psychotherapy which lasts up to 40 interviews. He has also demonstrated convincingly and brilliantly that he obtains successful results even with patients who have serious psychopathology and whom we would not have considered to be good candidates for STAPP. Mann (1973), with his 12-interview "time-limited psychotherapy," is able to deal successfully with individuals who have problems with separation and for whom his type of treatment is ideally suited.

Davanloo (1978) has ingeniously developed a broad-focused brief dynamic psychotherapy for individuals with incapacitating phobias and obsessive-compulsive symptomatology which, by creating a therapeutic alliance and then dealing head on with the defenses over a period of several months, is able to help them cope with the conflicts underlying their difficulties and to produce an impressive psychodynamic resolution of their problems. 
There are others who offer modified forms of brief dynamic psychotherapy, such as Bellak and Small (1965), Barten (1971), McGuire (1965a,b, 1968; McGuire \& Sifneos, 1970), Notman, Stracker, and many more in the United States and Canada. In Europe, Schneider (1976) and his group in Lausanne, Heiberg and her collaborators in Oslo, and Pierloot, Luminet, and Meyer in their respective departments in Louvain, Liège, and Hamburg have developed techniques with very promising results.

It seems obvious, therefore, that we are dealing with a variety of psychotherapeutic interventions of short-term duration all using psychodynamic principles, with some more indicated in a population of neurotic individuals with circumscribed difficulties, while others offer help to somewhat more seriously disturbed neurotic patients.

This book is about STAPP. This kind of treatment involves a dyadic interaction between the patient and the therapist which has affective, cognitive, and educational components. It is a focal, goaloriented, psychodynamic psychotherapy which envisages that the patient is capable of cooperating with the therapist within the context of a therapeutic alliance, and is able to resolve the psychological conflicts underlying his difficulties. Thus the selection of appropriate candidates according to specified criteria is a sine qua non. The requirements for this treatment involve weekly, face-to-face interviews lasting 45 minutes. There is no specified number of interviews, nor is there a termination date set. Rather, the length of this therapy is tailor-made to fit each patient's time requirement to solve a specified problem which has been agreed upon between himself and his therapist. It may take $6,9,14$, or at most 20 interviews. Although it is clearly understood between the two participants that the treatment will be brief, its termination is left open-ended.

The nature of the psychological conflicts which are chosen to be resolved, and which underlie the patient's difficulties, are Oedipal or triangular. This implies that problems must have developed between the patient and his parents during early childhood and are being repeated in his current interpersonal relations. These problems have to do with a competition with the parent of the same sex for the love and affection of the parent, or a parent surrogate, of the opposite sex. Repetitive unsuccessful attempts to deal with these conflicts give rise to circumscribed symptoms and/or to well-delineated 
interpersonal difficulties, which act as a compelling force in making the patient seek help.

The technical therapeutic considerations for this kind of psychotherapy are specific and clear-cut. The therapist must encourage the development of a therapeutic alliance and must create an atmosphere where learning can take place. Taking advantage of the prevailing positive transference feelings, staying within the specified focus, and using anxiety-provoking confrontation questions, clarifications, and interpretations, he must strive to avoid getting entangled in pregenital characterological issues, such as passivity, dependence, sadomasochistic or narcissistic features, and acting-out tendencies which are used defensively by the patient and which tend to prolong the treatment.

With attention to both the cognitive and the emotional components, new learning, self-understanding, and problem-solving techniques are systematically taught to the patient so as to bring about a "corrective emotional experience" and a dynamic resolution of the Oedipus complex. Finally, and as soon as evidence is provided in terms of tangible examples that changes are actually taking place, the therapy must come to an end.

This book, then, will present a detailed and factual account of STAPP. The first part describes the typical complaints presented by the patients and enumerates the steps that must be taken for the proper evaluation of their psychological difficulties. These include a systematic developmental history taking, a specification of selection criteria, and the establishment of a therapeutic contract.

The second part deals with a detailed discussion of the specific therapeutic techniques which are utilized, and which have already been outlined. Finally, the third part describes briefly the supervision of those who want to learn to offer this kind of therapy and the results which can be expected. As often as possible, clinical examples to enrich the theoretical discussion will be presented from interviews with patients who were seen over a 20 -year period at the psychiatric clinics of the Massachusetts General and Beth Israel Hospitals of Harvard Medical School, and in my own private practice.

First and foremost, I want to express my gratitude to those patients who provided me with a rich clinical material without which this book would not have been possible. Careful attention has been 
paid in making all the necessary alterations to protect their confidentiality and to preserve their anonymity without distorting the relevance of the basic observations or the nature of the psychotherapeutic interactions.

To my close friend of many years, John Nemiah, I am deeply indebted for his cordial and continued encouragement in pursuing my work on STAPP in his department without any interference. It is a privilege for me to be a member of his department at Harvard, where an academic atmosphere predominates, where stimulating discussions take place, where novel ideas are developed, and where teaching and learning are possible. For all these things I want to express my appreciation to him.

Without the warm support, the careful reviewing, and the stimulating comments of my long-standing friend Freddy Frankel, this book would have been difficult to write. My special and grateful appreciation is deeply felt.

To George Fishman, for his meticulous attention to detail and for his stimulating discussion of my manuscript, I am grateful and indebted.

I am especially thankful to our short-term psychotherapy research team-Drs. Roberta Apfel, Ellen Bassuk, and Andrew Gillfor their constructive and critical discussions, both clinical and theoretical, and to Donald Fern, who was an active member of our team and whose loss is greatly felt.

The various therapists whom I had the privilege to supervise over many years, and who provided me with invaluable insights which I could utilize meaningfully in thinking about this therapy, have contributed greatly to my understanding of this treatment. I owe my thanks to them.

To my colleagues overseas-Drs. Habib Davanloo, Astrid Heiberg, Daniel Luminet, David Malan, Roland Pierloot, and Pierre Schneider and their assistants-I want to express my thanks for many thoughtful comments about short-term psychotherapy in general and my own work in particular.

Last but not least, however, to my secretaries, Beth Noonan and Phyllis Wiseman-gracious and patient-who deciphered my handwriting and on their own free time typed my manuscript, much credit is due. Their efforts are gratefully appreciated.

Finally, I want to express a feeling of prevailing helplessness 
when I try to recreate the lively atmosphere of the therapeutic interviews, or to recapture the warmth of the interaction with my patients. Adequate words cannot be found for the proper description of such a relationship. When the treatment comes to an end, however, the feelings of pride for a meaningful achievement and of sadness for the termination of a friendly relation usually give rise to an occasional tear which both patient and therapist want to hide, but which is evidence of the value and success of their brief human encounter.

Boston, Massachusetts

Peter E. Sifneos 


\section{Contents}

PART ONE: THE PSYCHIATRIC EVALUATION

1. Certain Common Complaints of Prospective STAPP

Patients .............................. 3

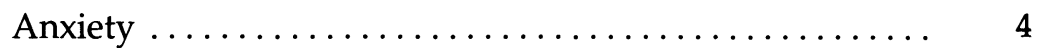

Anxiety in Conjunction with Other Symptoms ........ 6

Phobia with Obsessive Thoughts ................ 7

Grief Reaction ........................... 8

Mild Depression . . . . . . . . . . . . . . 9

Interpersonal Difficulties .................... 11

2. History Taking and Reformulation of the Presenting

Complaints........................... 15

History Taking. .......................... 16

Reformulation of the Patient's Presenting Complaints ... 20

3. Criteria for Selection for STAPP $\ldots \ldots \ldots \ldots \ldots \ldots \ldots$

Circumscribed Chief Complaint ............... 27

History of One Meaningful Relationship during the

Patient's Early Childhood .................. 30 
Flexible Interaction with the Evaluator and Ability to Express Feelings Openly during the Interview ......

Psychological Sophistication-Above-Average Intelligence and Psychological Mindedness ............ 39

Motivation for Change $\ldots \ldots \ldots \ldots \ldots \ldots \ldots \ldots \ldots . \ldots 2$

4. The Psychological Evaluation Process: Part III . . . . . . . 49

The Psychodynamic Formulation and the Assessment of Specific Predisposing Vulnerability .......... 49

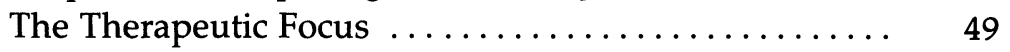

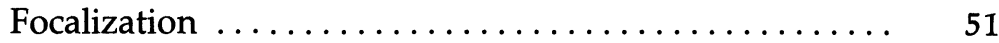

The Oedipal Therapeutic Focus............... 52

The "Therapeutic Contract" ................. 61

PART TWO: TECHNIQUE

5. The Opening Phase of STAPP $\ldots \ldots \ldots \ldots \ldots \ldots \ldots \ldots \quad 71$

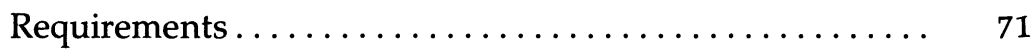

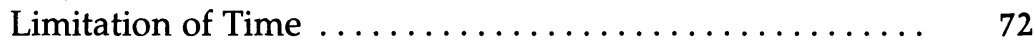

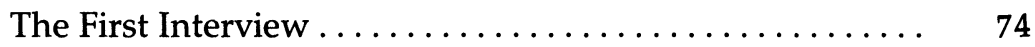

The Therapeutic Alliance ................ 78

The Therapeutic Value of a Single Interview ........ 82

6. Early Therapeutic Considerations $\ldots \ldots \ldots \ldots \ldots$...... 91

The Use of Positive Transference ............... 91

Countertransference: Occasional Difficulties ......... 106

The Sex of the Therapist................... 109

The Therapist's "Activity" in STAPP ............ 110

7. An Example of an Early STAPP Interview ........ 121

8. The Height of STAPP $\ldots \ldots \ldots \ldots \ldots \ldots \ldots \ldots \ldots \ldots$

The Therapeutic Focus and the Oedipus Complex..... 127 
The Use of Anxiety-Provoking Questions, Confrontations, and Clarifications ........................... 131

The Past-Transference Links ................. 134

Avoidance of Pregenital Characterological Issues Used Defensively by the Patient and of Development of Transference Neurosis .................. 142

New Learning and Problem Solving by the Patient, and the Therapist's Interpretations............... 146

9. The Height of the Therapy: A Case Example ........ 151

Short-Term Predictions between Sessions, and Note Taking ............................ 154

Tenth Interview ........................ 156

Eleventh Interview $\ldots \ldots \ldots \ldots \ldots \ldots \ldots \ldots \ldots \ldots \ldots \ldots$

Twelfth Interview. ...................... 161

Recapitulation at Times of Massive Resistance ........ 166

Support of the Patient Who Is Making Progress........ 166

Education of the Patient .................... 167

10. The Last Phase of STAPP: An Example of a Typical Interview .............................. 169

11. The Terminal Phase $\ldots \ldots \ldots \ldots \ldots \ldots \ldots \ldots \ldots \ldots, 175$

Evidence of Change and Development of Insight ..... 175

Who Initiates Termination? ................... 180

Absence of Ambivalence about Ending Treatment...... 182

PART THREE: RESULTS

12. Instruction in STAPP $\ldots \ldots \ldots \ldots \ldots \ldots \ldots \ldots \ldots$

Criteria for Becoming a STAPP Therapist ........... 189

The Nature of STAPP Supervision . . . . . . . . . . . 190

The Use of Videotape ........................ 192

Analysis of STAPP Technique ................. 195 
13. The Outcome of STAPP $\ldots \ldots \ldots \ldots \ldots \ldots \ldots \ldots . \ldots$

Early Studies $\ldots \ldots \ldots \ldots \ldots \ldots \ldots \ldots \ldots \ldots .200$

Psychotherapeutic Outcome.................. 202

Outcome Criteria ........................ 203

Recent STAPP Study ....................... 204

An Internalized Dialogue .................... 208

14. STAPP for Older Patients and Individuals with Physical Symptomatology

15. Epilogue

Appendix I

Evaluation Interview $\ldots \ldots \ldots \ldots \ldots \ldots \ldots \ldots \ldots .217$

First Therapy Interview .................... 223

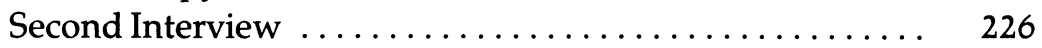

Third Interview $\ldots \ldots \ldots \ldots \ldots \ldots \ldots \ldots \ldots \ldots \ldots .228$

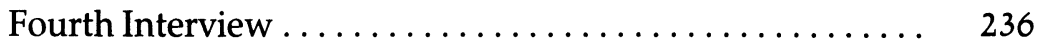

Fifth Interview . . . . . . . . . . . . . . . . . . 237

Sixth Interview ........................ 239

Seventh Interview....................... 250

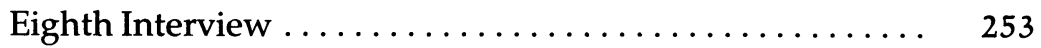

Ninth Interview . . . . . . . . . . . . . . . . . . . . 259

Tenth Interview . . . . . . . . . . . . . . . . . . . 266

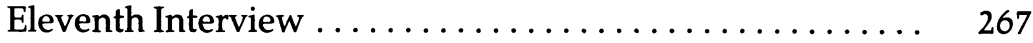

Follow-Up Interview ..................... 273

Appendix II ............................. 277

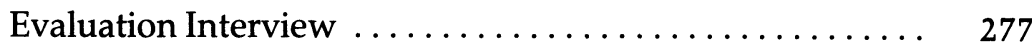

First Interview . . . . . . . . . . . . . . . . . .

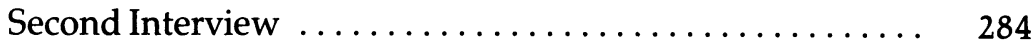

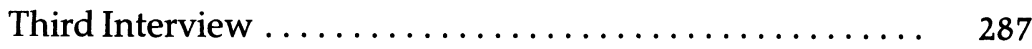

Fourth Interview . . . . . . . . . . . . . . . . . 290

Fifth Interview . . . . . . . . . . . . . . . . . . 293 
Sixth Interview ........................ 296

Seventh Interview . . . . . . . . . . . . . . . . . 298

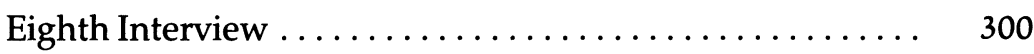

Ninth Interview....................... 301

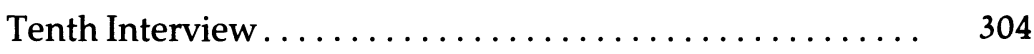

Thirteenth Interview .................... 306

Follow-Up Interview $\ldots \ldots \ldots \ldots \ldots \ldots \ldots \ldots \ldots \ldots, \quad 307$

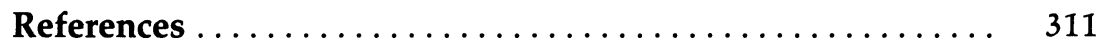

Index $\ldots \ldots \ldots \ldots \ldots \ldots \ldots \ldots \ldots \ldots \ldots \ldots \ldots \ldots \ldots \ldots \ldots \ldots, \quad 315$ 